\title{
The impact of stock market and macroeconomic variables on real estate prices dynamics: evidence from Saudi Arabia
}

\author{
Mohammed S. Al Dohaiman \\ Al Imam Mohammad Ibn Saud Islamic University (IMSIU), \\ College of Administration and Finance, \\ Saudi Electronic University, Saudi Arabia \\ Email: mdohaiman@gmail.com
}

\begin{abstract}
To enhance portfolio return and achieve diversification, Saudi investors have long been seeking opportunities in real estate markets since the crash of Saudi stock market on February 2006. The aim of this paper is to explain the determinants of real estate price dynamics in the case of Saudi Arabia. Using monthly data from January 2008 to December 2012, we examine the impact of key monetary policy and macroeconomic variables, including money supply growth, inflation rates and interest rate, on the real estate price growth dynamics in Saudi Arabia. We study also the effect of stock market conditions (return and conditional volatility) on explaining real estate price movement. This study has important implications for investment decision and real estate market analysis in the case of an important real estate market.
\end{abstract}

Keywords: real estate; monetary policy; stock market; quantile regression.

Reference to this paper should be made as follows: Al Dohaiman, M.S. (2017)

'The impact of stock market and macroeconomic variables on real estate prices dynamics: evidence from Saudi Arabia', Int. J. Sustainable Real Estate and Construction Economics, Vol. 1, No. 1, pp.3-15.

Biographical notes: Mohammed Al Dohaiman is an Assistant Professor of Finance. Currently, he is the Dean of the College of Administrative and Financial Sciences at Saudi Electronic University.

\section{Introduction}

Saudi Arabia is a vital country in the Arab Middle East with the largest real estate market in the GCC countries. Saudi Arabia's economic fundamentals are strong with Real GDP growth averaged $6.25 \%$ per annum during 2008-2012, third behind China and India, despite the difficult global economic environment. It is forecast to become one of the best performing real estate markets in the few next. In Saudi Arabia, real estate plays a crucial role in the non-oil economy. The investment of real estate is especially preferred after the crash of local stock market on February 2006, due to traditional values and to the region's high income and population density. The prices of real estate (especially housing prices) are rising. Social and cultural factors play an important part on housing preferences. 
According to special report "Housing the growing population of the Kingdom of Saudi Arabia" (2013), Saudi Arabia has been compared with similar countries in terms of population, GDP, and income levels. Based on this comparison, only $30 \%$ of the Saudi population own homes, a ratio below that of many emerging economies, while the global average stands at $70 \%$ (KCORP, 2013).

Rising housing real estate prices in Saudi Arabia in recent years have drawn much attention. The housing market continues to expand on the back of high economic growth, favourable population demographics, and increasing urbanisation. Although the growing attention from investors and policy makers, research on the housing market in Saudi Arabia has been very limited. This paper analyses the effect of monetary policy and financial market on real estate price movement using linear quantile regression. The classical least squares and maximum likelihood estimators are only accepted for Gaussian distributions and present only a conditional mean view of the relationship. Quantile regression methods seek to broaden this view and offer a more complete characterisation of the stochastic relationship among variables and providing more robust and consequently more efficient, estimates in some non-Gaussian distribution. Thus, this paper has two main objectives. The first objective is to examine the impact of stock market, oil price, and key monetary policy variables on the real estate price growth dynamics in Saudi Arabia. The second goal is to explore if the effect of variables change across quantiles.

This paper makes two contributions to the related literature on real estate markets. First, we find evidence that the stock return volatility co-moves with the real estate prices in bullish markets. Second, the oil price co-moves with real estate prices in the bearish and bullish market, implying an asymmetric effect Then, the use of nonlinear models like quantile regression can detect the dependence structure and the dynamics in the upper and lower tails of the distribution and this result can be generalised in real estate price dynamics analysis.

The rest of the paper is organised as follows: Section 2 discusses the literature review. Section 3 presents quantile regression methodology. Section 4 presents data and preliminary statistics. Section 5 presents estimation results and discussion. Finally, Section 6 concludes.

\section{Literature review}

\subsection{The relationship between real estate and macroeconomic variables}

Many studies show that macroeconomic variables explain real estate price dynamics. Quan and Titman (1999) find that real estate prices are influenced by GDP growth rates and provide a good long-run hedge against inflation. The anticipation of domestic currency appreciation, relatively higher interest rate, and robust domestic home price growth, foreign 'hot money' has flown to real estate markets and can affects prices movements. Zhang and Fung (2006) find that lag one quarter 'hot money' flows affect positively the home price growth, without controlling for the impact of monetary policy variables such as interest rate or growth in money supply. Lizieri et al. (1998) show that real estate markets are considered as cyclical in nature. Xu and Chen (2012) explore the impact of key monetary policy variables including long-term benchmark bank loan rate, money supply growth, and mortgage credit policy indicator, on the real estate price 
growth dynamics in China. They find that decreasing interest rates lead to an acceleration of money supply growth. However, rising interest rates, slower money supply growth and tightening mortgage down payment policy tend to decelerate the subsequent home price growth.

\subsection{The relationship between real estate and stock markets}

A growing part of literature on the relationship between stock markets and real estate prices exists. Okunev et al. (2000) use causality approaches to examine the relationship between real estate and the stock market index in the USA. They find that the linear causality results were spurious that nonlinear, but that there was a strong unidirectional relationship running from the stock market to the real estate market. Okunev and Wilson (1997) show that the integration between real estate and stock markets may not be linear and they propose a nonlinear integration framework to test the relationship between the two markets. Wilson and Okunev (1999) study the relationship between stock and real estate markets in the USA, UK, and Australia. They find a co-integration relationship between the stock and real estate markets in the USA from 1971 to 1987, in the UK from 1988 to 1993 and no long-run relationship. $\mathrm{Fu}$ and $\mathrm{Ng}$ (2001) find that real estate prices in Hong Kong are slower in adjusting to economic news relative to the stock market. The slow adjustment may induce serial autocorrelation in real estate price growth and a positive correlation between lag stock market return and real estate price growth. Quan and Titman (1999) study the relationship between stock and real estate markets in 17 countries over 14 years and find that the relationship between real estate and stock returns is not statistically significant, except in Japan. Lin and Lin (2011) analyse the integration relationship between stock markets and real estate markets in six economies (Japan, Singapore, South Korea, Taiwan, China, and Hong Kong). They find that that the stock market is integrated with the real estate market in Japan, but is fractionally integrated with the real estate markets in China, Hong Kong, and Taiwan. However, the stock market and real estate market is segmented in South Korea and Singapore. Zhang and Fung (2006) study the linkages between real estate and stock market returns in China. They find that the two markets are systematically negatively related due to fund flows.

\section{Methodology and research design}

The quantile regression model introduced by Koenker and Bassett (1978) is presented as follows:

$$
Y=X^{\prime} \beta+\varepsilon \quad \text { with } \quad Q_{y}(\tau / X)=X^{\prime} \beta(\tau)
$$

where $Y$ is the dependent variable, $X$ a vector of exogenous variables, and $Q_{y}(\tau / X)$ denotes the $\tau^{\text {th }}$ conditional quantile of $Y$, assumed to be linearly dependent on $X$.

More formally, any random variable ' $y$ ' may be characterised by its distribution function $F(y)=\operatorname{Prob}(Y \leq y)$, while for any $0<\tau<1, Q(\tau)=\inf \{y: F(y) \geq \tau\}$ is called the $\tau^{\text {th }}$ quantile of $Y$. The quantile function provides a complete characterisation of the random variable. More formally, taking a random sample $y_{1}, y_{2}, y_{3}, \ldots y_{n}$ with the 
empirical distribution function $\hat{F}_{y}(\alpha)=\frac{1}{n} \neq\left\{y_{i} \leq \alpha\right\}$, the empirical unconditional quantile function is defined as

$$
\hat{Q}_{y}(\tau)=\hat{F}_{y}^{-1}(\tau)=\inf \left\{\alpha / \hat{F}_{y}(\alpha) \geq \tau\right\}
$$

According to Koenker and Bassett (1978), the quantiles may be expressed as the solution to a minimisation problem:

$$
\begin{aligned}
\hat{Q}_{y}(t) & =\arg \min _{\alpha}\left\{\sum_{i: y_{i} \geq \alpha} \tau\left|y_{i}-\alpha\right|+\sum_{i: y_{i}<\alpha}(1-\tau)\left|y_{i}-\alpha\right|\right\} \\
& =\arg \min _{\alpha} \sum_{i} \rho_{\tau}\left(y_{i}-\alpha\right)
\end{aligned}
$$

Using the check function

$$
\rho_{\tau}(z)= \begin{cases}\tau z: & z \geq 0 \\ (\tau-1) z: & z<0\end{cases}
$$

In the case of linear dependence on a vector of exogenous variables $(X)$, the linear conditional quantile function can be written as follows:

$$
Q_{y}(\tau / X)=\inf \left\{\alpha / F_{y}(\alpha / X) \geq \tau\right\}=\sum_{k} \beta_{k}(\tau) X_{k}=X^{\prime} \beta(\tau)
$$

In this study, the vector of exogenous variables includes macroeconomic variables (represented by long-term benchmark bank loan rate, money supply growth, interest rate, stock market return and volatility). We evaluate Saudi Arabia real estate movements across seven quantiles $q=\{0.05 ; 0.1 ; 0.25 ; 0.5 ; 0.75 ; 0.9 ; 0.95\}$, which include the median $(50 \%)$.

\section{Data description and empirical model}

\subsection{Data description}

The first dataset used in this study consists of monthly real estate price index from Saudi Arabia covering the period from June 2010 to March 2015. We use S\&P Saudi Arabia real estate index obtained from DataStream database. The S\&P Saudi Arabia real estate price index is a standalone index designed to capture $80 \%$ or more of the local market capitalisation. Constituent stocks are the largest and most liquid of the listed universe.

Figure 1 plot the dynamics of S\&P Saudi Arabia real estate price index from June 2010 to March 2015.

The second dataset consists of monthly Saudi Arabia stock index returns (Tadawul All Share Index, TASI) for the same period, obtained from the Saudi Stock Exchange (TADAWUL). Figure 2 plots the TASI returns from June 2010 to March 2015. 
Figure 1 Real estate price dynamics from June 2010 to March 2015 (see online version for colours)

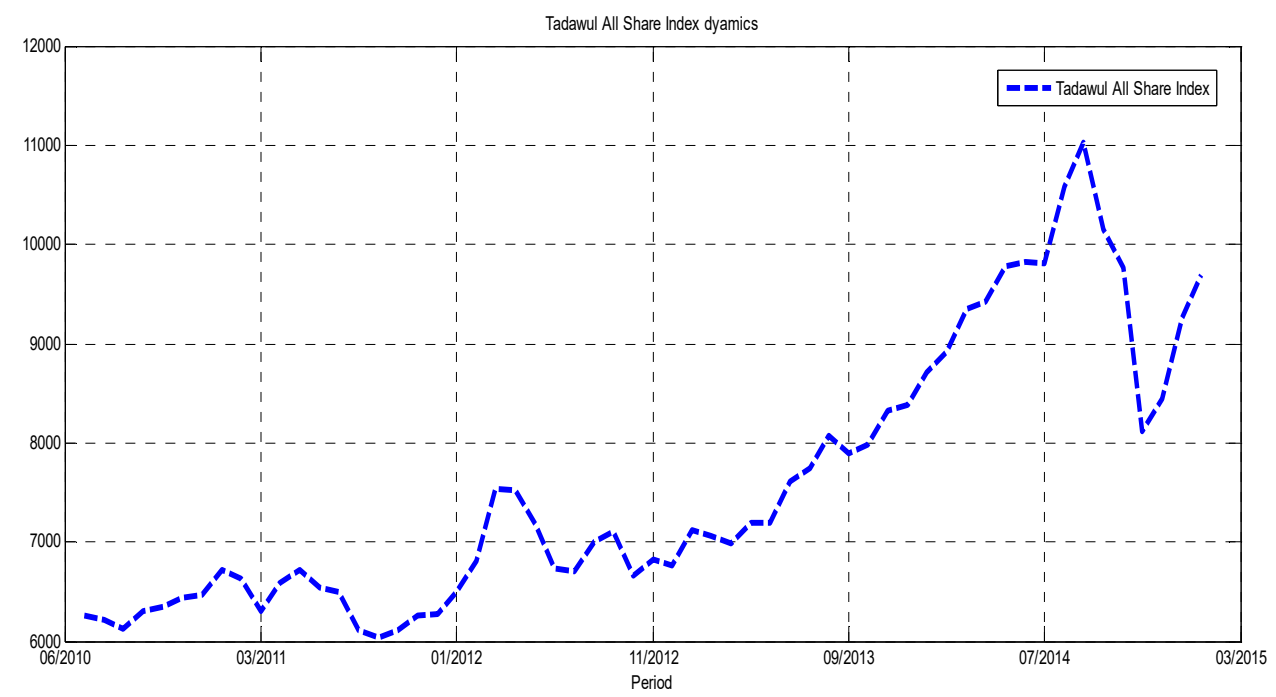

Figure 2 Real estate price dynamics from June 2010 to March 2015 (see online version for colours)

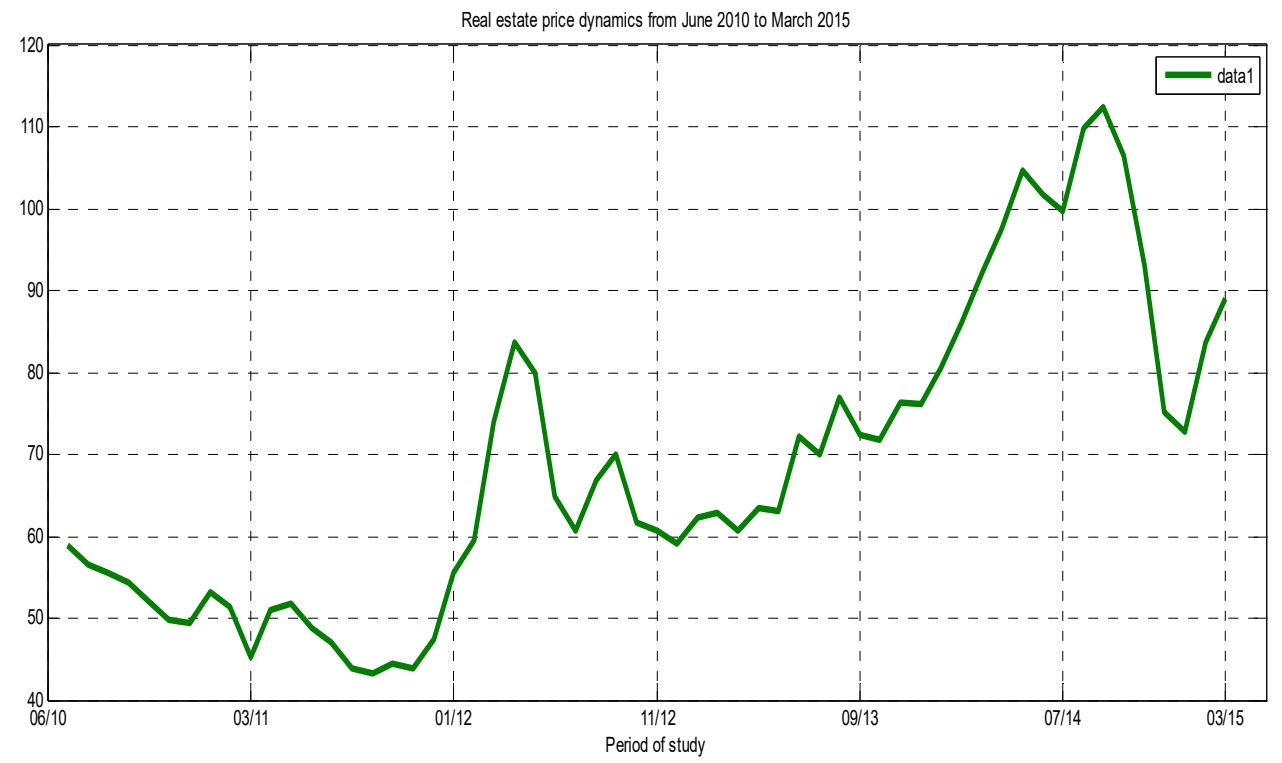

The third dataset consist of conditional volatility of stock returns. We estimate the monthly stock return index volatility using $\mathrm{EGARCH}(1,1,1)$. The most popular approach for modelling conditional volatility is the GARCH family of models, as introduced by Engle (1982) and generalised by Bollerslev (1986) and Nelson (1991). GARCH models are attractive because of their simplicity and empirical success in modelling time-varying volatility in different contexts. The Exponential GARCH [EGARCH, Nelson (1991)] is presented as follows 


$$
\operatorname{Ln}(h)_{t}=w+\alpha \frac{\left|\varepsilon_{t-1}\right|}{\sqrt{h_{t-1}}}+\gamma \frac{\varepsilon_{t-1}}{\sqrt{h_{t-1}}}+\beta \ln \left(h_{t-1}\right)
$$

where $\omega$ is the unconditional variance that satisfies the condition $\omega>0, \varepsilon_{t}$ is the innovation in the levels model and $h_{t}$ is the conditional variance. The parameter $\gamma$ is the asymmetry parameter that satisfies the condition $-1<\gamma<1$. Figure 3 plots the estimated volatility with EGARCH model.

Figure 3 Volatility estimation with EGARCH (see online version for colours)

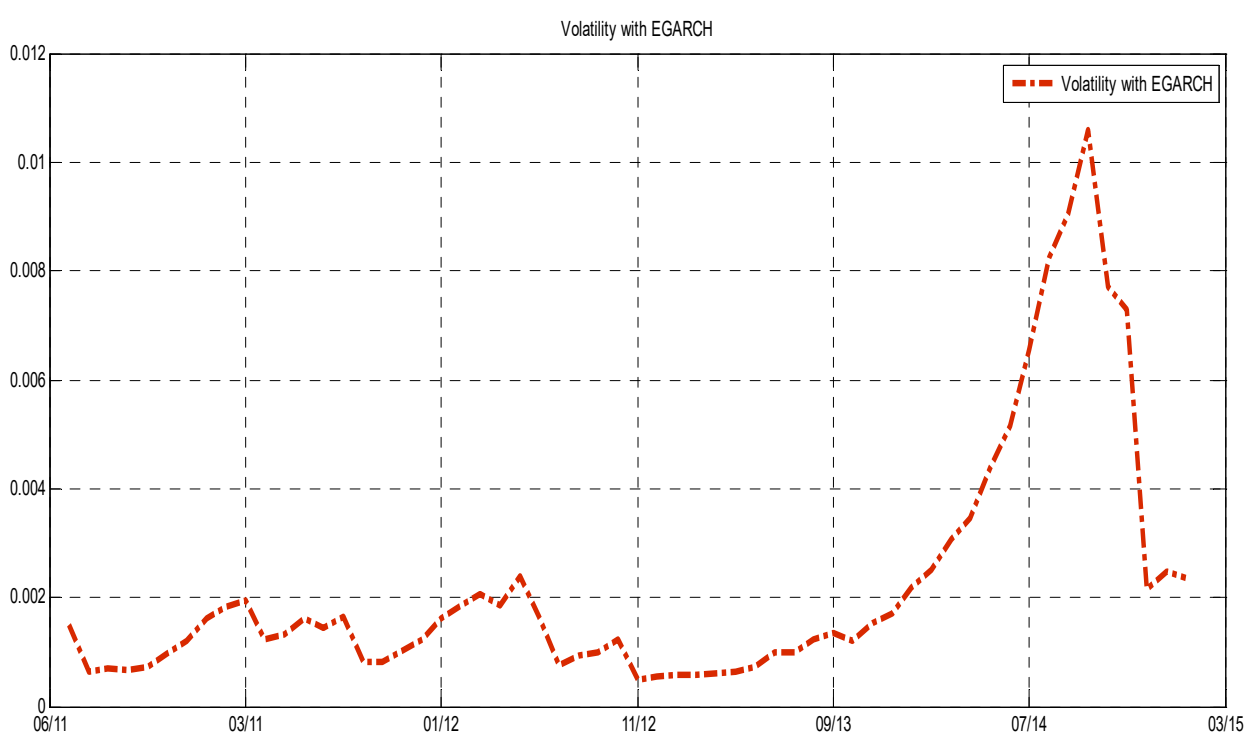

Figure 4 SIBOR dynamics from June 2010 to March 2015 (see online version for colours)

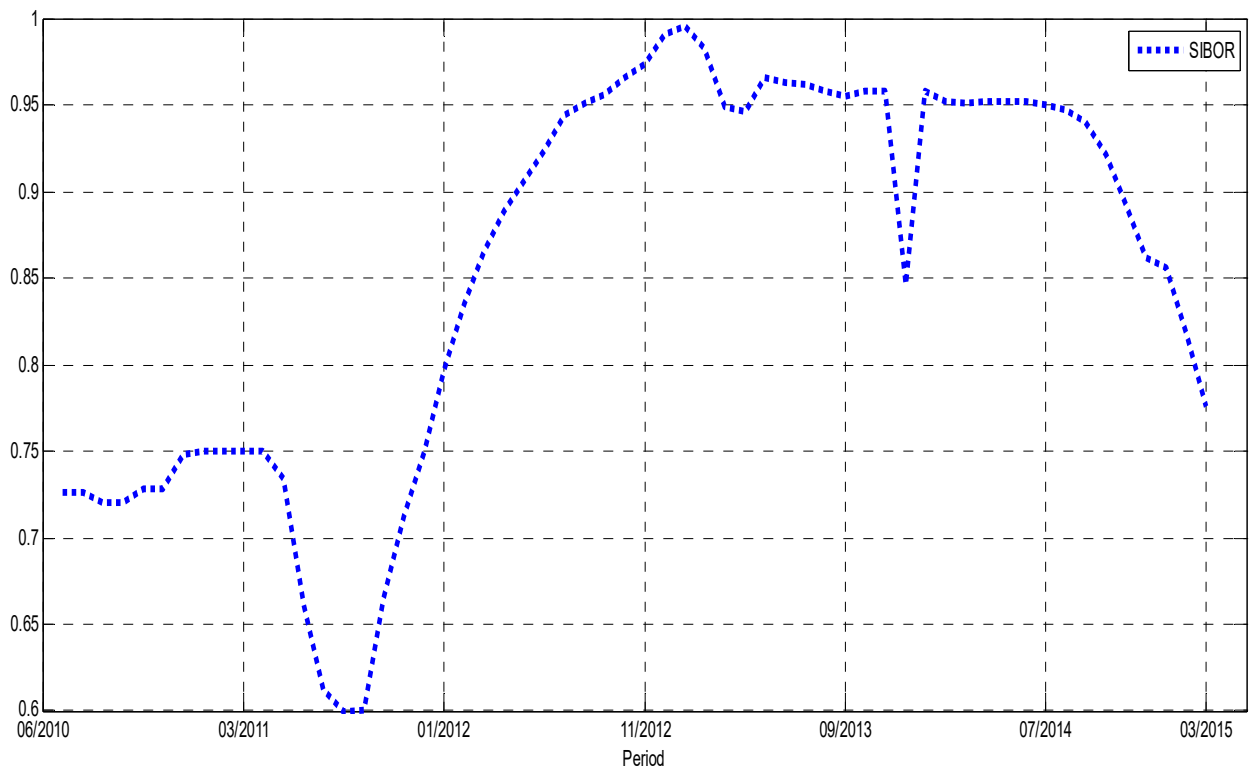


The fourth dataset consist of short term interest rate (Saudi Interbank Offering Rate, SIBOR). Changes in interest rates may affect the real return from lending and the real cost of borrowing, at least in the short term. Figure 4 plots de dynamic of SIBOR during the period of the study.

The fifth dataset consists of inflation rates. Consumer price index (CPI) is used as a proxy for inflation rates. Figure 5 plots the movement of inflation rates during the period of the study.

Figure 5 CPI dynamics from June 2010 to March 2015 (see online version for colours)

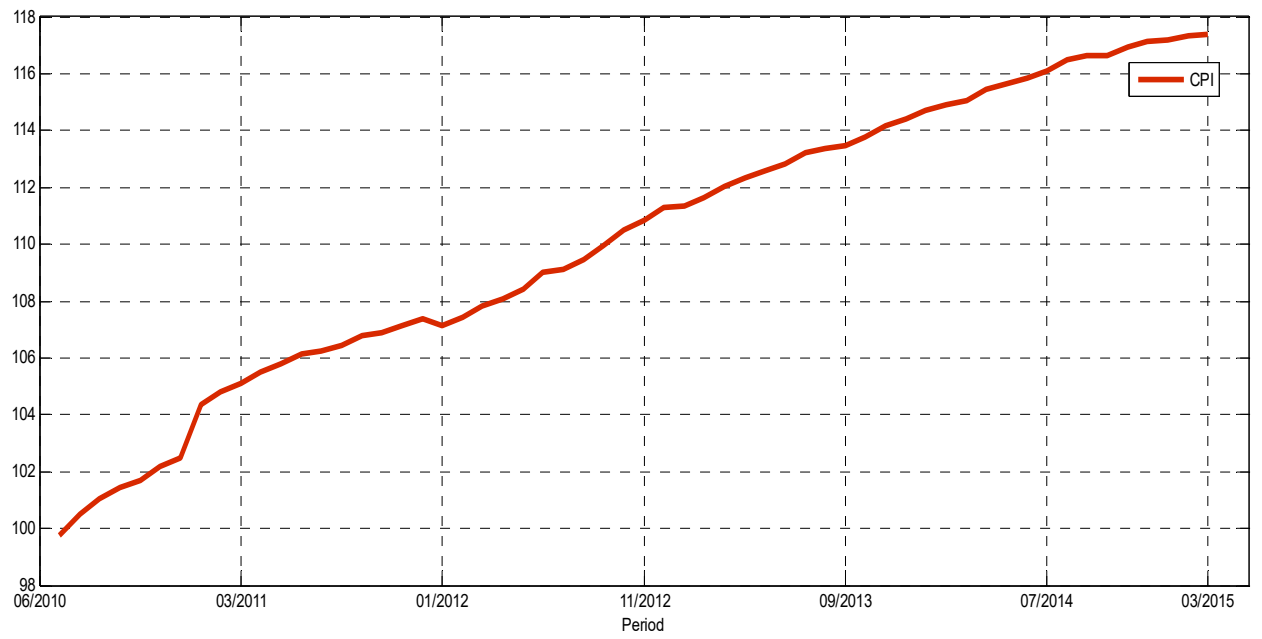

Figure 6 Money supply (M3) dynamics from June 2010 to March 2015 (see online version for colours)

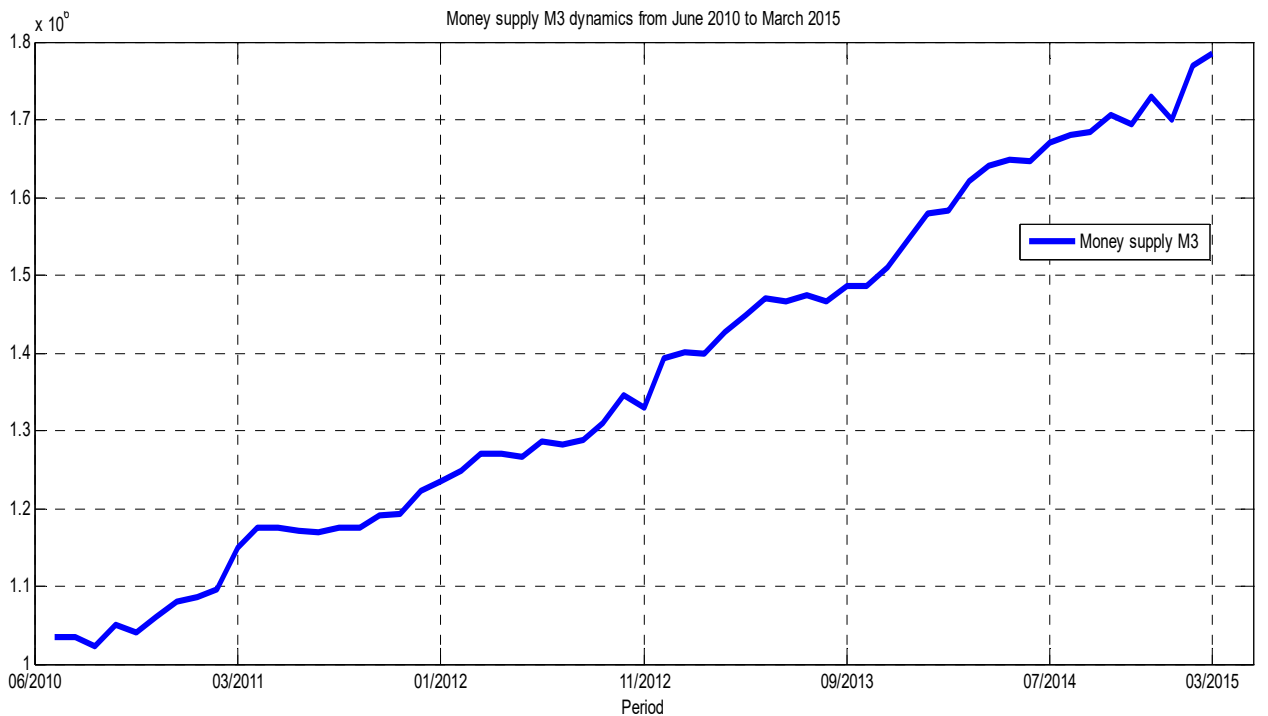

The sixth dataset consist of money supply M3 growth rate. The money supply represents the entire stock of currency and other liquid instruments in a country's economy as of a 
particular time. Economists analyse the money supply and develop policies revolving around it through controlling interest rates and increasing or decreasing the amount of money flowing in the economy. The money supply M3 measurement includes assets that are less liquid than other components of the money supply, and are more closely related to the finances of larger financial institutions and corporations than to those of businesses and individuals. Figure 6 plots the dynamics of money supply (M3) in Saudi Arabia from June 2010 to March 2015.

Finally, we also use monthly OPEC oil spot prices as a proxy for economic development because Saudi Arabia remains the world's largest producer of crude oil and is the only country with significant spare production capacity. Figure 7 plots the dynamics of oil prices during the period of the study. Figure 7 plots the dynamics of crude oil prices during the period of the study.

Figure 7 Crude oil prices dynamics from June 2010 to March 2015 (see online version for colours)

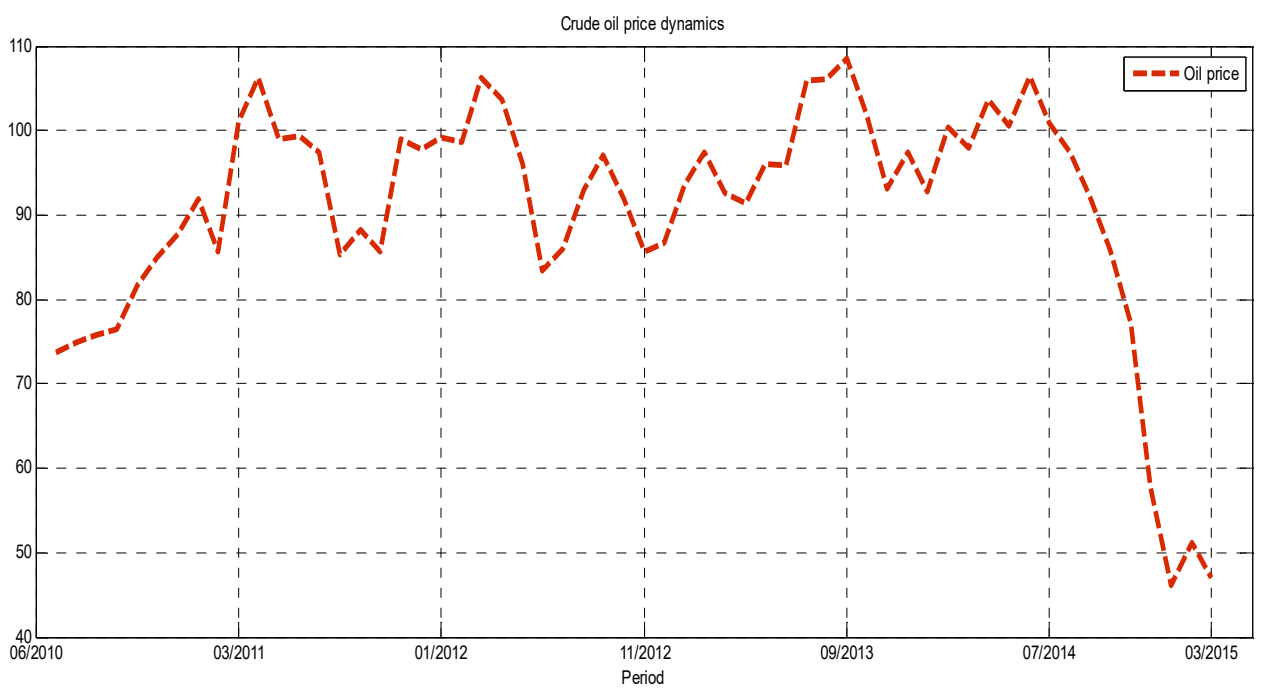

Table 1 Descriptive statistics

\begin{tabular}{lccccccc}
\hline & $R E I$ & $S R$ & $S R V$ & $I N T$ & $M S$ & $I N F$ & OP \\
\hline Mean & 68.56207 & 0.006385 & 0.002217 & 0.854190 & $1,371,568$. & 110.1624 & 90.63241 \\
Std. dev. & 63.26500 & 0.009516 & 0.001466 & 0.898900 & $1,337,922$. & 110.6750 & 93.30000 \\
Maximum & 112.4700 & 0.102828 & 0.010593 & 0.995700 & $1,785,279$. & 117.3830 & 108.6000 \\
Minimum & 43.33000 & -0.184691 & 0.000479 & 0.600000 & $1,023,425$. & 99.76900 & 46.07000 \\
Skewness & 18.70282 & 0.046139 & 0.002285 & 0.116741 & $226,491.7$ & 5.076057 & 14.02901 \\
Kurtosis & 0.675999 & -1.239549 & 2.166590 & -0.601997 & 0.174969 & -0.292648 & -1.580592 \\
Jarque-Bera & 25.52517 & 67.66461 & 68.74287 & 20.21439 & 18.00957 & 20.04232 & 55.14912 \\
\hline
\end{tabular}

Notes: Monthly data for the period June 2010 to March 2013. REI is real estate index; SR is stock return volatility; SRV is stock return volatility measured by EGARCH; MS is money supply; INF is inflation rate and OP is crude oil prices. 
Table 1 summarises the preliminary statistics from these data. We note from this table that real estate index averages at 68.56 points and that the skewness measure is positive for all series which shows that excess-return time series are skewed to the right. The Jarque-Bera test shows that the null hypothesis of normality is rejected for all series. Figure 8 gives the quantile-quantile plots for the data, and none of the data series show a good fit to normal distributions. Then, if the data distribution is not normal, quantile regression can provide more efficient estimates for the relationship among Saudi Arabia real estate index, monetary policy and financial market variables.

Figure 8 Q-Q plot of the data (see online version for colours)
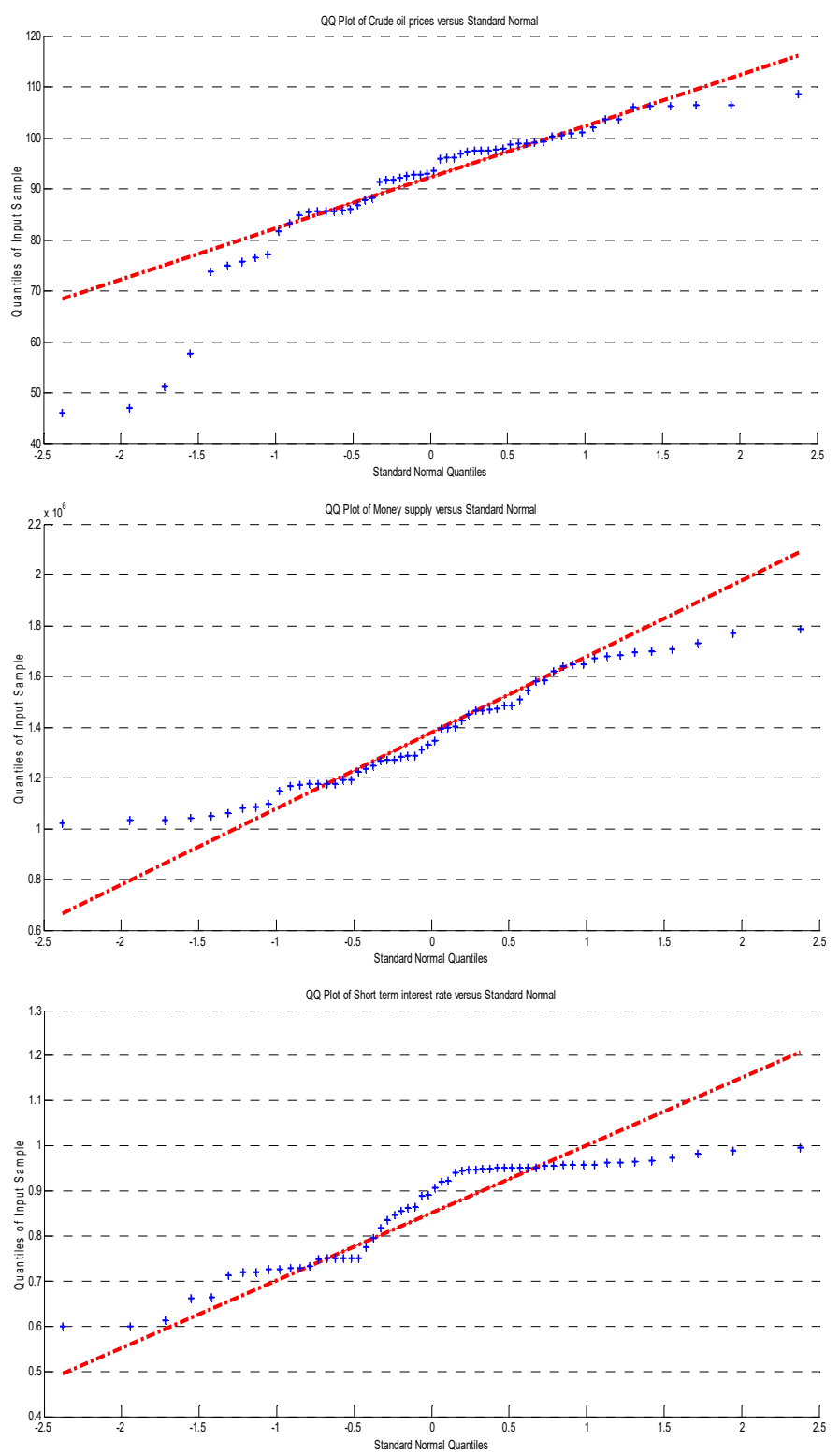
Figure 8 Q-Q plot of the data (continued) (see online version for colours)
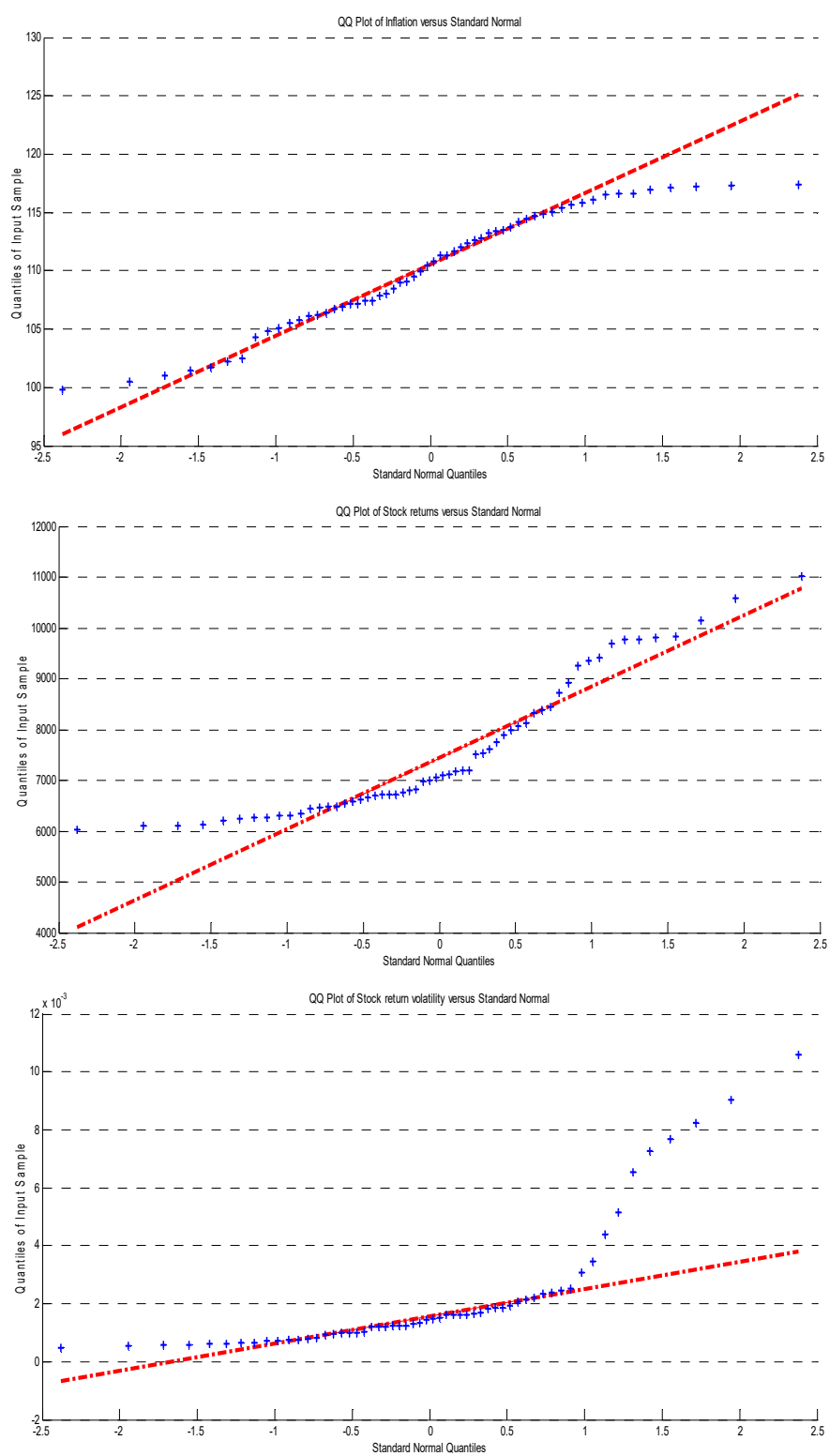

\subsection{Empirical model}

To account for market co-movements between real estate index dynamics and different macroeconomic variables, we postulated a model for the $\tau$ quantile of the distribution of real estate index dynamics: 


$$
Y=X^{\prime} \beta+\varepsilon \quad \text { with } \quad Q_{y}(\tau / X)=X^{\prime} \beta(\tau)
$$

where $Y$ is the dependent variable, $X$ a vector of exogenous variables, and $Q_{y}(\tau / X)$ denotes the $\tau^{\text {th }}$ conditional quantile of $Y$, assumed to be linearly dependent on $X$.

Quantile regression does not require any distribution assumptions regarding the population and can estimate the parameters non-parametrically. The estimation of the conditional mean using OLS is extended to a similar estimation of an ensemble of models of various conditional quantile functions for data distribution (Allen et al., 2012).

\section{Estimation results and discussion}

We evaluate effect of monetary policy and financial market on real estate price movement across seven quantiles. The estimation results of equation (5) are presented in Table 2. We note that the effect of the stock market returns is positive and significant for all quantiles of the real estate market. However, the impact of stock return volatility is significant only for the intermediate and upper tail dependence. This implies that the structure of dependence is asymmetric, having upper tail dependence. The relationship between real estate dynamics and inflation is significant but only in the upper side. Thus, faster growth in inflation rates lead to the acceleration of residential price growth. The rate of inflation affects the real cost of borrowing and the real return from lending and would therefore affect the balance sheets of real estate firms and households. The coefficients of crude oil prices (used as a proxy for government spending) are significant for upper and lower quantiles and indicate a positif impact on residential real estate prices. This implies that he structure of dependence is asymmetric, having upper tail dependence and lower tail independence.

Table 2 Quantile regression estimates for the Saudi Arabia real estate index

\begin{tabular}{lccccc}
\hline & $Q(0.10)$ & $Q(0.25)$ & $Q(0.50)$ & $Q(0.75)$ & $Q(0.90)$ \\
\hline $\mathrm{REI}_{\mathrm{t}-1}$ & 0.8029 & 0.7917 & 0.8766 & 0.94060 & 0.9342 \\
$\mathrm{SR}_{\mathrm{t}}$ & $0.9091^{*}$ & $0.9960^{*}$ & $0.1065^{*}$ & $0.9710^{*}$ & $0.93643^{*}$ \\
$\mathrm{SRV}_{\mathrm{t}}$ & 0.4637 & 0.5626 & $0.7498^{*}$ & $0.6242^{*}$ & $-0.1067^{*}$ \\
$\mathrm{INT}_{\mathrm{t}}$ & -1.0542 & -0.1523 & 0.1839 & -0.2898 & -0.1283 \\
$\mathrm{MS}_{\mathrm{t}}$ & 0.1127 & 0.4514 & 0.2528 & 0.6418 & 0.5298 \\
$\mathrm{INF}_{\mathrm{t}}$ & 0.3481 & 0.9571 & 0.6803 & $0.2129^{*}$ & $0.1693^{*}$ \\
$\mathrm{OP}_{\mathrm{t}}$ & $0.1323^{*}$ & $0.0405^{*}$ & 0.0142 & $0.1032^{*}$ & $0.0954^{*}$ \\
Constant & -0.1961 & 0.1788 & 0.8766 & 0.3372 & 0.4810 \\
Pseudo $R^{2}$ & 0.8110 & 0.8209 & 0.8353 & 0.8615 & 0.8704 \\
\hline
\end{tabular}

Notes: This table presents the quantile regression parameter estimates for the model described in equation (5). The numbers in parentheses are the bootstrapped standard errors. The asterisk $(*)$ denotes statistical significance at the $5 \%$ level. 


\section{Conclusions}

Using monthly data from January 2008 to December 2012, this paper examines the impact of stock market conditions and key monetary and macroeconomic variables on the real estate price behaviour in Saudi Arabia. Using quantile regression approach, the main finding of the empirical study is that the stock return volatility co-moves with the real estate prices in bullish markets, while money supply and interest rate variables have no effects on the Saudi Arabia real estate price dynamics. On the other hand, the oil price co-moves with real estate prices in the bearish and bullish market, implying an asymmetric effect. Then, the use of nonlinear models like quantile regression can detect the dependence structure and the dynamics in the upper and lower tails of the distribution.

\section{References}

Allen, D.E., Singh, A.K., Powell, R.J., McAleer, M., Taylor, J. and Thomas, L (2012) The Volatility-Return Relationship: Insights from Linear and Non-Linear Quantile Regressions, Edith Cowan University Working Paper No. 1201.

Bollerslev, T. (1986) 'Generalized autoregressive conditional heteroskedasticity', Journal of Econometrics, Vol. 31, No. 3, pp.307-327.

Dickey, D.A. and Fuller, W.A. (1979) 'Distribution of the estimators for autoregressive time series with a unitroot', J. Am. Stat. Soc., Vol. 74, No. 366, pp.427-431.

Engle, R. (1982) 'Autoregressive conditional heteroskedasticity with estimates of United Kingdom inflation', Econometrica, Vol. 50, No. 4, pp.987-1008.

Fu, Y. and Ng, L.K. (2001) 'Market efficiency and return statistics: evidence from real-estate and stock markets using a present value approach', Real Estate Economics, Vol. 29, No. 2, pp.227-250.

KCORP (20013) Housing the Growing Population of the Kingdom of Saudi Arabia, Special report [online] http://jeg.org.sa/data/modules/contents/uploads./infopdf/2040.pdf.

Koenker, R. (2005) Quantile Regression, Cambridge University Press, New York.

Koenker, R. and Bassett Jr., G. (1978) 'Regression quantiles', Econometrica, Vol. 46, No. 1, pp.33-50.

Koenker, R. and Hallock, K. (2003) 'Quantile regression', Journal of Economic Perspectives, Vol. 15, No. 4, pp.143-156.

Kwiatkowski, D., Phillips, P.C.B., Schmidt, P. and Shin, Y. (1992) 'Testing the null hypothesis of stationary against the alternative of a unit 523 root', J. Econ., Vol. 54, pp.159-178, North-Holland.

Lin, T.C. and Lin, Z.H. (2011) 'Are stock and real estate markets integrated? An empirical study of six Asian economies', Pacific-Basin Finance Journal, Vol. 19, No. 5, pp.571-585.

Liu, C. and Mei, J. (1998) 'The predictability of international real estate markets, exchange rate risks and diversification consequences', Real Estate Economics, Vol. 25, No. 2, pp.193-221.

Liu, C.H., Hartzell, D.J. and Hoesli, M.E. (1997) 'International evidence on real estate securities as an inflation hedge', Real Estate Economics, Vol. 25, No. 2, pp.193-221.

Lizieri, C., Worzala E. and Johnson, R. (1998), To Hedge or Not to Hedge? A Study of International Real Estate under Exchange Rate Uncertainty, The Royal Institution of Chartered Surveyors, June.

Nelson, D.B. (1991) 'Conditional heteroskedasticity in asset returns: a new approach', Econometrica, Vol. 59, pp.347-370. 
Okunev, J. and Wilson, P. (1997) Using Nonlinear Tests to Examine Integration between Real Estate and Stock Markets, Real Estate Economics, Vol. 25, pp.487-503.

Okunev, J., Wilson, P. and Zurbruegg, R. (2000) 'The causal relationship between real estate and stock markets', Journal of Real Estate and Economics, Vol. 21, No. 3, pp.251-261.

Opoku, R.A. and Abdul-Muhmin, A.G. (2010) 'Housing preferences and attribute importance among low-income consumers in Saudi Arabia', Habitat International, Vol. 34, No. 2, pp.219-227.

Quan, D. and Titman, S. (1999) 'Do real estate prices and stock prices move together? An international analysis', Real Estate Economics, Vol. 27, No. 2, pp.183-207.

Schweizer, B. and Wolff, E.F. (1981) 'On nonparametric measures of dependence for random variables', Annals of Statistics, Vol. 9, No. 4, pp.879-885.

Wilson, P.J. and Okunev, J. (1999) 'Long-term dependencies and long run non-periodic co-cycles: real estate and stock markets', Journal of Real Estate Research, Vol. 18, No. 2, pp.257-278.

Xu, X.E. and Chen, T. (2012) 'The effect of monetary policy on real estate price growth in China', Pacific-Basin Finance Journal, Vol. 20, No. 1, pp.62-77.

Zhang, G. and Fung, H-G. (2006) 'On the imbalance between the real estate market and the stock market in China', The Chinese Economy, Vol. 39, No. 2, pp.26-39. 